\title{
THE INSPIRATION OF SUBORDINATE LABOURS FOR ENRICHED MANAGEMENT
}

\author{
Dr. C K GOMATHY, Ms.CHITTURI.CHAITANYA, Ms.BANDI JAHNAVI \\ Sri Chandrasekharendra Saraswathi Viswa Mahavidyalaya, Kanchipuram
}

\begin{abstract}
Junior workers are indispensable, vital post of management and need to be motivated for efficiency and effective productivity.This research work is on motivation of junior workers for enhanced performance focused on selected firms(PHCN,Sports Council,ITC) in Owerri.The study identified the problems of motivation on junior workers. The study has four research questions and two Hypothesis, both primary and secondary sources of data where used.Filed source design was used while structural questionnaire is the major instrument for data collections. The questionnaire was analyzed with simple percentage with chi-square statistical tool.The study revealed that motivation influences the junior workers performance and that its constituent determine it acceptance a compensation policy.Based on the findings it was recommended that management should re-appraise and re-evaluate the present salary structure of junior workers with a view to increasing its productivity and in order to achieve it and maintained it.
\end{abstract}

\section{Keywords:}

Motivation,Productivity,Performance,Junior workers.

\section{I . INTRODUCTION}

Human Beings, whatever their background and orientationmay be, are motivated in one way or the other. There are various reasons why people work. To earn respect among associates. To earn salaries and wages. To acquire prestige and honour. To achieve excellence in choosen a carrer. To socialize with other.That culture is indeed a determining factor.According to mescon et al (1999) stated that motivation is the force that moves individuals to take action. It is the set of forces that initiate behaviour and determine its form, direction intensity and duration.No wonder in trying to explain the meaning of motivation by kootz, he said that motivation is an inner state that energizes activities of moves and that directs or channels behaviour towards goal accomplishment. The presence of motivation in any form in whatever field on human endeavour, enhnace performance and in many cases increases productivity. A worker who is motivated will not only be happy with her job but also will in addition give or put in her best in the work. She will seek better way to perform any function and increase her for creativity,innovation as well as have a sense of belonging in that particular organization. After all, the essence of hardwork is to derive some rewards. This study is there for intended to highlight how motivation 
effects the productivity of workers in general and junior workers in particular.

\section{II.PROBLEM STATEMENT}

This study is set to identify motivational techniques employed by organization to enhance the performance of their junior workers. It will also identify the prospects and constraints of techniques while recomending the most effective of them all. Some of this problems are, use of wrong incentives, application of technique, lack of experts or professionals in the field and this causes low productivity. As a result of this it becomes necessary for some organization to resort in order to enhances the performance of their workers.

\section{III . PURPOSE OF THE STUDY}

This study is designed effectively to evaluate impact of motivation on junior workers in relation to performance. If they are some experts in the field, it will help in increasing productivity. Use of incentive will help to motivate workers to achieved enhanced performance. The application of modern techniques or machines helps workers to perform their work so easier and increase productivity.

\section{IV.DEFINITION OF TERMS}

Junior: Somebody or person younger, lower in rank or position than other in an organization.

Workers: A person who work, especially one who does a particular kind of work or is a person who takes part of the productivity process.
Junior Workers: From the two definitions above, junior workers are defined as a persons of lower rank who works in an organization.

Motivation: The process of influencing or encouraging subordinate or followers to work for a cause designed by the motivator or leader or it is an inner state that energizes activities of moves on that directs or channels behaviour towards goal accomplishment.

Performance: It is a faithful commitment to doing or executing ones responsibilities in an organization.

Productivity:It is the rate at which a worker, a company or a country produces goods and the amount produced, compared with how much time,work and money as needed to produce them.

\section{V.SIGNIFICANT STUDY}

Employees are valuable profit making thought of a business organization. According to A.U ohiri "A truly motivated workers is one who wants to work". This means that if one is adequately motivated, one will not discharge his duties well. Management should bear in mind that if workers were not properly motivated, there level of productivity would drop.

Therefore, this study will go along way by providing a framework on how to motivate workers adequate using only resources of the employers, ascertain the effect of motivation on the workers in election to productivity at work places.It will help the workers and management to draw a distinction between monetary incentives and other motivational techniques such as fringe benefits and advancement applied as in inducement to junior workers work enhancement inorder to boost productivity. 


\section{VI.CONCLUSION}

The study concludes that it is designed effectively to evaluate imapct of motivation on junior workers in relation to performance.

\section{VII.REFERENCES}

1.Dr.C K Gomathy, Article: A Study on the recent Advancements in Online Surveying, International Journal of Emerging technologies and Innovative Research ( JETIR ) Volume 5 | Issue 11 | ISSN : 2349-5162, P.No:327-331, Nov-2018

2.Dr.C.K.Gomathy,C K Hemalatha, Article: A Study On Employee Safety And Health

Management International Research Journal Of Engineering And Technology (Irjet)- Volume: 08 Issue: 04 | Apr 2021

3. Dr.C K Gomathy, Article: A Study on the Effect of Digital Literacy and information Management, IAETSD Journal For Advanced Research In Applied Sciences, Volume 7 Issue 3, P.No-51-57, ISSN NO: 2279-543X,Mar/2018

4. Dr.C K Gomathy, Article: An Effective Innovation Technology In Enhancing Teaching And Learning Of Knowledge Using Ict Methods, International Journal Of Contemporary Research In Computer Science And Technology (Ijcrcst) E-Issn: 2395-5325 Volume3, Issue 4,P.No-10-13, April '2017
5.Dr.C K Gomathy, Article: Supply chain-Impact of importance and Technology in Software Release Management, International Journal of Scientific Research in Computer Science Engineering and Information Technology ( IJSRCSEIT ) Volume 3 | Issue 6 | ISSN : 2456-3307, P.No:1-4, July-2018

\section{AUTHOR'S PROFILE:-}

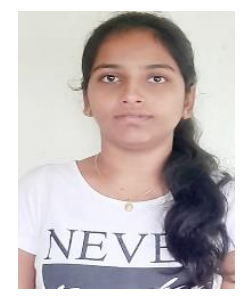

1. Ms.Chaitanya Chitturi, Student ,B.E. Computer Science and Engineering, Sri Chandrasekharendra Saraswathi Viswa Maha Vidhyalaya Enathur, Kanchipuram,India. Her area of interest in Human Resources Development

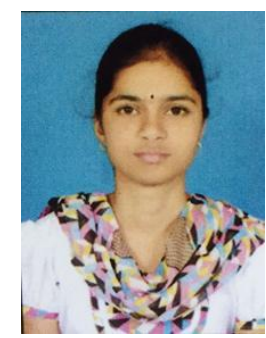

2.Ms.Bandi Jahnavi, Student, B.E Computer Science and Engineering , Sri Chandrasekharendra Saraswathi Viswa MahaVidyalaya,Enathur, Kanchipuram, India. Her area of interest in Human Resources

Development.

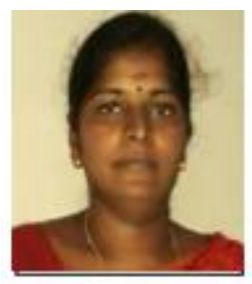

3.Dr.C.K.Gomathy is Assistant Professor in Computer Science and Engineering at Sri Chandrasekharendra Saraswathi

ViswaMahaVidyalaya,Enathur,Kanchipuram,India. Her area of interest in Software Engineering, Web Services, Knowledge Management and IOT. 